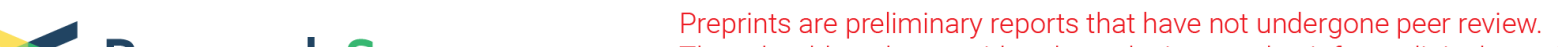 $\begin{array}{ll}\text { Research Square } & \text { They should not be considered conclusive, used to inform clinical practice, } \\ \text { or referenced by the media as validated information. }\end{array}$
}

\section{Type of physical training and selected aspects of psychological functioning of women with obesity: a randomised trial}

Monika Bąk-Sosnowska ( $\sim$ monika.bak-sosnowska@sum.edu.pl)

Medical University of Silesia https://orcid.org/0000-0003-4970-0545

Magdalena Gruszczyńska

Department of Psychology, Medical University of Silesia in Katowice

Damian Skrypnik

Department of Treatment of Obesity, Metabolic Disorders and Clinical Dietetics, Poznan University of Medical Sciences

\section{Sławomir Grzegorczyn}

Department of Biophysics, Medical University of Silesia in Katowice

Joanna Karolkiewicz

Department of Food and Nutrition, Poznan University School of Physical Education

\section{Marzena Ratajczak}

Department of Anatomy, Poznan University School of Physical Education

\section{Edyta Mądry}

Department of Physiology, Poznan University of Medical Sciences

Jarosław Walkowiak

Department of Pediatric Gastroenterology and Metabolic Disease, Poznan University of Medical

Sciences

\section{Paweł Bogdański}

Department of Treatment of Obesity, Metabolic Disorders and Clinical Dietetics, Poznan University of Medical Sciences

\section{Research article}

Keywords: obesity, physical activity, psychological aspects, body image

Posted Date: January 3rd, 2020

DOI: https://doi.org/10.21203/rs.2.20007/v1

License: (c) (1) This work is licensed under a Creative Commons Attribution 4.0 International License.

Read Full License 
Version of Record: A version of this preprint was published at Nutrients on July 26th, 2021. See the published version at https://doi.org/10.3390/nu13082555. 


\section{Abstract}

Background: We have conducted a prospective randomised trial to check whether a specific type of regular physical training done by women with obesity is related to obtaining specific psychological benefits.

Methods: Participants were patients of outpatient clinic suffering from obesity. Finally, 44 women were qualified for the study and divided into two groups: $A(n=22)$ and $B(n=22)$. The applied intervention consisted of regular 3-month physical exercises in the form of endurance training (group $A$ ) or endurancestrength training (group B). Initially and after the completed intervention, anthropometric measurements were carried out in each group (height, weight, waist circumference, hip circumference), BMI and WHR were calculated, the level of psychological parameters was examined: stress (PSS-10), general selfesteem (SES), body self-report (BSQ-34, FRS), behaviours associated with diet (TFEQ-18).

Results: At baseline, groups did not differ in age (A: $M=51.3, S D=8.3$ yrs.; $B: M=48.2, S D=11.2$ yrs.) and BMI (A: $M=35.2, S D=3.9 \mathrm{~kg} / \mathrm{m} 2 ; B: M=34.9, S D=3.8 \mathrm{~kg} / \mathrm{m} 2$ ). As a result of the intervention, both groups had significantly lower anthropometric parameters and FRS decreased significantly with regard to the current figure (gr. $A: p<0.001$; gr. $B: p=0.01$ ) and $B S Q-34$ result (gr. $A: p=0.001 ;$ gr. $B: p=0.01$ ). Additionally, group $B$ had lower results in TFEQ-18 in terms of cognitive restraint $(p=0.01)$ and emotional eating $(p=0.01)$. There were no differences between group $A$ and $B$ in terms of the magnitude of changes achieved due to the intervention, except from significant improvement $(p=0.03)$ in group $A$ in terms of perception of the current figure (FRS).

Conclusions: Three-months long regular physical activity of women with obesity promotes the perception of own body as slimmer and lower body shape concerns. Endurance-strength training enhances cognitive and emotional control in the field of nutrition, it also seems more beneficial in reducing stress levels. In turn, the change in body shape is more noticed under the influence of endurance training. Trial registration: Clinical Trials NCT03444207 Keywords: obesity, physical activity, psychological aspects, body image

\section{Background}

Physical activity is recommended as one of the key methods of reduction of excessive body weight, in addition to caloric restrictions. It helps improve control of type 2 diabetes (T2D) [1] and cardiovascular diseases (CVD) [2], reduces serum glucose levels and blood pressure, improves overall quality of life [3], reduces insulin resistance [4], concentration of proinflammatory cytokines [5] and the risk of cancer [6], helps maintain physical fitness [7]. The benefits of physical activity are observed in obese persons even when they do not reduce their body weight significantly because maintaining a high level of cardiorespiratory fitness reduces the risk of obesity-related diseases [8]. Additionally, it helps elderly patients maintain the appropriate length of telomeres as an indicator of biological cellular aging [9]. However, it is not occasional physical activity that is more strongly associated with a number of 
anthropometric and mortality outcomes, but a consistent pattern of high physical activity [10]. Research shows that, although physical activity brings measurable health benefits regardless of gender, in the case of women positive health can be observed already in low (<3 MET) or moderate (3-6 MET) intensity of exercises done for 15 minutes a day [11].

In the case of overweight persons (BMI 25-29.9 kg/m²), 45 to 60 minutes are recommended, while for obese persons $\left(\mathrm{BMI} \geq 30 \mathrm{~kg} / \mathrm{m}^{2}\right)$ from 60 to 90 minutes of moderate physical activity on most days of the week [12]. It is estimated that regular aerobic physical activity for less than 150 minutes a week only prevents further weight gain, and for 150-225 minutes a week results in a slight weight loss $(2-3 \mathrm{~kg})$. Only more than 225 minutes (to 420 minutes) of regular activity per week brings weight reduction at the level of $5-7.5 \mathrm{~kg}$ in the observation period. In order to maintain the results achieved, it is recommended to maintain regular moderate physical activity for 200-300 minutes per week [13].

Endurance training is recommended for obese people. However, it brings satisfactory results at the level of $5-15 \%$ reduction in the initial body weight only when it is combined with caloric restrictions [14]. Even if it does not result in significant weight loss, it improves glucose and lipid metabolism in people leading a sedentary lifestyle before [15]. In turn, sole strength training is considered to be ineffective in reducing excess body weight. However, it should be noted that it brings measurable health benefits such as reduction of body fat mass, increase in muscle mass, improvement of the lipid profile [16]. The comparison of women with abdominal obesity doing three times a week for three months in endurance training or mixed endurance-strength training had beneficial effects in terms of anthropometric parameters, body composition, physical fitness and cardiovascular function [17], liver [18] and kidney parameters [19], as well as the significant impact of the above-mentioned training programs on mineral balance [20], functional skills and back pain [21].

Physical activity is beneficial for both somatic functions and for mental health [22] and the efficiency of psychological mechanisms, even in terms of motivation, self-efficacy or self-regulation [23]. This is particularly important in the case of obese persons because this disease is often accompanied by depression, reduced quality of life and self-esteem, shame related to the appearance, withdrawal from social relations and other psychological problems [24]. The relationship between perception of own appearance and self-esteem, overall mental well-being and eating behaviour is significant especially in women [25]. Scientific reports confirm psychological benefits arising from endurance training in persons with excessive body weight. They concern, inter alia, lowering depression, improved mood and overall self-esteem [26]. Similar effects can also be brought by less intense Pilates training [27] or yoga [28]. On the other hand, a meta-analysis comparing results of 17 studies on the impact of strength training on the mental state of obese people has not showed any convincing evidence of such an effect. A slight effect was observed in relation to aspects such as self-esteem, inhibition, anxiety or depression [29].

Comparison of psychological benefits resulting from both types of physical training in a group of obese people is not studied sufficiently. The available results mainly concern the level of depression, anxiety and quality of life and indicate no significant differences between groups doing endurance training and 
endurance-strength training [30,31]. Therefore, the aim of our study was to compare the influence of endurance training, and endurance-strength training on stress, self-esteem, body-esteem and eating behaviour in women with obesity. The innovative nature of the study is related to the use of the comparative intervention model (endurance vs endurance-strength) and to the analysis of the impact of these two training models on the psychological state of women with obesity.

\section{Method}

The study was a part of an interdisciplinary research project for which consent of the Bioethics Committee of the Medical University in Poznań was obtained (No. 1077/12 with supplement No. 753/13).

This work was supported by the National Science Centre, Poland, Grant No. 2014/13/B/NZ7/02209 and the Faculty of Medicine I, Poznan University of Medical Sciences, Poland, Grant for Young Scientists [grant number 502-14-01119172-41123].

The study has been registered as a clinical trial on 23 February, 2018 on ClinicalTrials.gov under the ID NCT03444207. The trial protocol can be accessed at https://clinicaltrials.gov/ct2/show/NCT03444207.

\section{Participants}

The study was conducted among 163 persons registered in the outpatient clinic of the Department of Internal Medicine, Metabolic Disorders, and Hypertension, University of Medical Sciences, Poznań, Poland. Inclusion criteria relevant to the issues presented in this study were as follows: 1 . informed and written consent to participate in the study; 2 . age from 18 to $65 ; 3$. Diagnosed obesity (BMI $\geq 30 \mathrm{~kg} / \mathrm{m}^{2}$ ); 4. Stable body weight for a month before the study (acceptable deviation $\pm 1 \mathrm{~kg}$ ). Exclusion criteria relevant for this paper were as follows: 1 . Intellectual disability; 2 . Mental illness currently or in medical records. 3. Pregnancy, child-birth and lactation. The full list of criteria is presented in the publication by Skrypnik and co-authors ${ }^{17}$. Finally, 44 people were qualified for the study.

\section{Study Design}

The study was a prospective randomised trial. The study group was divided into two subgroups (group A and group B), using a randomisation list. Patients enrolment was performed by the physician. Patients were assigned to study intervention by the physician using subject's unique code according to random allocation sequence generated by computer. Groups did not differ in age, body mass, BMI, waist and hip circumference, WHR [17]. Both groups participated parallel in physical training for 3 months. Group A ( $n=$ $22)$ took part in endurance training, while group $B(n=22)$ in endurance-strength training. The subjects were informed about the necessity to keep the diet unchanged. Based on a dietary interview and with the use of specialised software for product consumption analysis, it was found that nutrient intake, total calories and caffeine intake during the study in both groups were at a constant, comparable level. 
Initially and after 3 months of physical training, measurements of body weight, height, waist and hips were carried out [17]. The following psychological parameters were also assessed: stress level, overall self-esteem, body self-esteem, eating behaviour. The study was carried out by diagnostic survey method using standardised questionnaires:

Perceived Stress Scale (PSS-10) by Cohen, Kamarcki, Mermelstein in Polish adaptation by Juczyński and Ogińska-Bulik. The scale examines the general stress level. It contains 10 questions concerning various subjective feelings associated with problems and personal experiences, behaviours and ways of dealing with them. The respondent marks the answers on a 4-point scale ( 0 - never, 1 - hardly ever, $2-$ sometimes, 3 - quite often, 4 - very often). The total score is the sum of all points and the higher the score, the higher the examined person's stress intensity. The total score, after conversion in accordance with the guidelines of the authors into standardised units, is interpreted as low (1-4 sten), average (5-6 sten), high (7-10 sten).

The Rosenberg Self-Esteem Scale (SES) by Rosenberg in Polish adaptation by Dzwonkowska, LachowiczTabaczek, Łaguna. The scale examines the level of overall self-esteem. It is composed of 10 diagnostic statements to which the respondents refer on a four-point scale (1 - I definitely agree, 2-I agree, 3-I have no opinion, $4-$ I do not agree, 4 - I definitely do not agree). The final score is the sum of all points and the higher the score, the higher the level of self-esteem of the examined person. The total score can be converted into sten units and interpreted analogously in accordance with the guidelines of the authors, as described above.

Body Shape Questionnaire (BSQ - 34) by Cooper, Taylor, Cooper, Fairburn. The questionnaire examines the level of preoccupation with their own body shape. It is composed of 34 questions. Each question has a 6-point scale of answers which reflects the frequency of experiencing the described situations by the subject in the last 30 days (1-never, 2-rarely, 3-sometimes, 4-often, 5-very often, 6-always). The sum of points gives the total score allowing classification of the examined person in accordance with the authors' guidelines, in one of the 4 categories describing concern with their body shape: none, mild, moderate, considerable.

Figure rating scale (FRS) by Stunkart. The scale examines perception of the size and shape of own body. It presents nine schematic silhouettes of men and women, from extremely thin to extremely obese. Subjects are asked to choose the silhouette that best reflects their Current Silhouette $(\mathrm{Cl})$ and Ideal Silhouette (IS) physical appearance. In the presented study, only female silhouettes were used due to the study group specificity.

The Three-Factor Eating Questionnaire-18 (TFEQ-18) by Karlsson, Persson. The questionnaire is used for measuring eating behaviour. The subject responds to the questionnaire using a 4-grade scale ( 0 definitely not, 1- rather not, 2- rather yes, 3- definitely yes). The scores are calculated separately for three sub-scales: Cognitive Restraint of Eating (CR), Uncontrolled Eating (UE), Emotional Eating (EE). The higher the score achieved in the given sub-scale, the greater intensity of the behaviour tested is manifested.

The occurrence of any exclusion criteria (mentioned above) during the trial resulted in immediate cessation of participation in the study. 


\section{Intervention}

Intervention was planned for three months. During this time, the tested women participated in physical training 3 times a week. Each group had 36 training sessions. Training took place in a professional sports club Sport Club City Zen in Poznań and was conducted by a qualified and certified fitness instructor. Both groups were also under medical supervision. Trainings of both groups included the following exercises:

Group A - endurance training on bicycle ergometers (Schwinn Evolution, Schwinn Bicycle Company, Boulder, CO, USA). Training sessions consisted of 5 minutes of warm-up including stretching exercises of low intensity (50-60\% of maximum heart rate); 45 minutes of training with intensity between 50 and $80 \%$ of maximum heart rate; 5 minutes of riding a cycloergometer without load and 5 minutes of low intensity stretching and breathing exercises.

Group B - endurance-strength training which consisted of a 5-minute warm-up (stretching exercises) of low intensity (50-60\% of maximum heart rate), 20 minutes of strength exercises, 25 minutes of endurance exercises (50-80\% of maximum heart rate), 5 minutes of cycling without a load and 5 minutes of stretching and breathing exercises.

As part of strength exercises, the participants did some variable, repeated weekly exercises with a barbell and exercises with a gym ball. Endurance exercises were done on cycloergometer (Schwinn Evolution, Schwinn Bicycle Company, Boulder, CO, USA). The heart rate during training was monitored using a Suunto Fitness Solution ${ }^{\circledR}$ (Suunto, Vantaa, Finland) device. Exact description of the intervention is presented in the publication by Skrypnik and co-authors [17].

\section{Statistical analysis}

Statistica 13.1 statistical package was used. Normality of distributions was tested using Shapiro-Wilk test. Statistical methods were used to compare groups for primary and secondary outcomes, as well as for subgroup analysis (e.g. difference between the initial and end value of variables, correlations between variables).

Parametric tests (t-Student, Pearson correlation coefficient) were used for the analysis of variables with normal distribution and, in the case of lack of normality in variables distribution - nonparametric tests (Wilcoxon signed-rank test, Mann-Whitney U test, Spearman's rank correlation coefficient). The adopted level of significance was $\mathrm{a}<0.05$.

\section{Results}

During the intervention 6 subjects- one from group $A$ and five from group $B$, were withdrawn from the trial due to poor compliance. 38 patients (group $A n=21$; group $B n=17$ ) completed the study and underwent statistical analysis (Fig. 1).

a place for Fig. 1 
As a result of the intervention used, significant changes in anthropometric parameters were observed in both groups, which were presented already in the paper by Skrypnik et al. [17]. With regard to psychological parameters after the intervention, there was a perception of the current figure as significantly slimmer and a significant reduction in level body shape concerns in both groups. Additionally, eating behaviour improved in group B, namely the level of cognitive restraint increased and emotional eating level decreased. Details are presented in the table below (Table 1).

a place for Table 1

Although the stress level (PSS-10) and self-esteem (SES) level did not change significantly in any group, distributions of results have changed. With regard to stress, the number of people experiencing low stress levels increased and the number of people experiencing average stress levels has decreased in both groups. Moreover, the number of people experiencing high stress levels decreased in group B (Fig. 2A, 2B).

a place for Fig. $2 \mathrm{~A}$

a place for Fig. 2B

In the case of general self-esteem, the number of people with high self-esteem increased in both group. In the categories of low and average self-esteem, changes were clearer and beneficial in group B (Fig. 3A, 3B).

a place for Fig. 3A

a place for Fig. 3B

The difference between the initial and end value (delta- $\delta$ ) as calculated for each analysed variable. It was observed that the more the level of self-esteem ( $\delta$ SES) increased among the subjects, the larger was the reduction in the following: BMI ( $r=-0.438)$, waist circumference $(r=-0.349), E E(r=-0.330)$ and BSQ-24 $(r=-0.377)$. Moreover, the more the level of body shape concerns ( $\delta$ BSQ-24) decreased, the more waist circumference $(r=0.393)$, WHR $(r=0.379)$, UE $(r=0.446)$ and CS $(r=0.362)$ decreased. Additionally, the bigger the difference in perception of current silhouette in the subjects $(\delta C S)$, the bigger the change in BMI $(r=0.375)$.

Also differences between the groups that implement different forms of physical training were examined with regard to the size of change $(\delta)$ in the analysed variables. Only the size of change in the perception of current silhouette differentiated both groups in favour of group A. Details concerning all the analysed variables are presented in Table 2.

a place for Table 2

\section{Discussion}


All the subjects after three months of regular physical training, regardless of the form of exercises done, had significant changes in the scope of objective parameters. They body weight decreased, just like their waist and hips circumference as well as the BMI and WHR. Certainly, all this decided about the perception of current silhouette and decreased levels of body shape concerns. The importance of BMI and WHR for psychological women's well-being results from the fact that both parameters are related to physical health and affect the assessment of physical attractiveness made by men when choosing their partners [32]. The researchers do not agree which one is more important for assessment of the attractiveness of female silhouette. For instance, Furnham et al. studied different models of female silhouette, differing in body weight, WHR and breast size. They assessed the impact of specific patterns on the assessment of women's attractiveness, femininity, health and fertility. They showed that effect sizes were higher for WHR (0.34-0.52) than for body weight (0.14-0.31). Major effects were not showed at all for breast size [33]. Also Płatek and Sighn confirmed, using fMRI, that men's brain reward centre activated in response to naked female bodies with surgically redistributed fat tissue to achieve optimal (approx. 0.7) WHR, with relatively unchanged BMI [34]. In turn, Holliday et al. also confirmed using fMRI a clearer response from the reward centre for both men and women when the subjects assessed the attractiveness of female silhouettes differing in BMI, not WHR [35].

However, research confirms clearly that both body shape improvement (expressed as a decrease in WHR) and body mass reduction (corresponding to BMI reduction) in obese women have a positive impact on the level of satisfaction with own body and reduce the concerns related to appearance [36,37]. In our study, we did not prove significant improvement in self-esteem of the subjects. However, we observed a tendency of its improvement, especially in the group doing endurance-strength training. In turn, the positive effect of excessive weight reduction on self-esteem is generally recognised [38]. On the other hand, most women show signs of dissatisfaction with own body regardless of their objective body weight, and the level of this dissatisfaction is higher in overweight and obese women [39]. Dissatisfaction with appearance and worrying about own body shape has a strong negative effect in women on the overall sense of self-respect and on behaviour, including nutrition [40]. In the psychological aspect, specific manifestations of eating behaviour can indicate the risk or occurrence of eating disorders. For instance, cognitive restraint of eating, consisting of deliberately abstaining from eating or limiting food intake in order to control the body weight and body image. Uncontrolled eating, in turn, is manifested in a tendency of overeating due to unrestrained hunger. Emotional eating is characterised by overeating resulting from depressed mood and anxiety. In own study, we confirmed the relationship between the intensity of body shape concerns and uncontrolled eating.

Although changes in the intensity of stress experienced by women participating in the intervention turned out to be statistically insignificant, we observed a clear trend associated with the increase in the number of persons experiencing low level of stress and a tendency of more favourable changes in this respect in women doing endurance-strength training. Studies confirm that obesity is associated with stress at both cellular level (oxidative stress) [41] and at psychological and social level [42]. The lack of clear changes in stress intensity before and after the intervention may be related to the assessment of achieved results as lower than expected by the subjects. The effort put into regular physical activity resulted, however, in 
reduction of objective somatic parameters but in the case of high initial body weight the changes may be less noticeable both for the subject and for her social environment. Occurrence of a mediating factor, between the change in appearance and appearance-related stress, can be another reason. The potential level of self-esteem, level of compassion towards herself or the level of depression could be such a factor. However, these hypotheses need to be confirmed in subsequent studies.

The main purpose of self-study was to specify whether the size of changes in selected psychological variables differs depending on the form of physical training. Endurance training develops such features as agility, speed, flexibility, nimbleness. It involves all muscle groups, improves functioning of the heart and the entire circulatory system. Endurance-strength training is additionally completed with resistance exercises, aimed at increasing muscle strength, bone strength and improving metabolism. We did not observe any significant differences in the size of psychological changes, except for assessing own current body shape, among the subjects implementing the above-mentioned forms of training for three months. Although self-esteem of the current silhouette shifted under the influence of training towards slimmer silhouette in both groups, the change was relevant only in women who did endurance training.

\section{Study strong points}

No similar studies have been found in scientific literature, which could be an area of comparison. It is only known that both types of training bring similar improvement in persons with excessive body weight in terms of depression and anxiety levels, and the quality of life [30, 31].

In our study we used an innovative, comparative intervention model of endurance vs endurance-strength training to analyse the impact of specific forms of physical activity on the psychological functioning of women with obesity. We applied restrictive inclusion and exclusion criteria that have resulted in a homogeneous group of participants. We have proved that both forms of training improve parameters related to body image, such as body percept and body concerns. Moreover, we found that endurancestrength training results in significant improvement in two psychological parameters affecting eating behaviour: emotional eating and cognitive restraint, as well as that this form of physical activity is conductive in better coping with stress. Our findings have a potential role in clinical implication of results in future recommendations for the treatment of obesity. They allow carefully for recommending of endurance-strength training for women with obesity as bringing more psychological benefits, in addition to measurable physiological changes.

\section{Study limitations}

The results obtained by us should be considered preliminary and requiring confirmation in a study intentionally designed to assess the changes in body image and eating behaviour under the influence of a particular type of physical activity. Another study will also provide an opportunity to correct the shortcomings that we could not avoid in this paper. The basic limitation of the study consists in a relatively small number of persons examined and a large age range. 


\section{Conclusions}

Three-months long regular physical activity of women with obesity promotes the perception of own body as slimmer and lower body shape concerns. Endurance-strength training enhances cognitive and emotional control in the field of nutrition, it also seems more beneficial in reducing stress levels. In turn, the change in body shape is more noticed under the influence of endurance training.

\section{Declarations}

\section{Ethical approval and consent to participate}

All procedures performed in studies involving human participants were in accordance with the ethical standards of the Bioethics Committee of the Medical University in Poznań and with the 1964 Helsinki Declaration and its later amendments. Informed written consent was obtained from all individual participants included in the study.

\section{Consent for publication}

Not applicable.

\section{Competing interests}

The authors declared no potential conflict of interest.

\section{Funding}

This work was supported by the National Science Centre, Poland, Grant No. 2014/13/B/NZ7/02209 and the Faculty of Medicine I, Poznan University of Medical Sciences, Poland, Grant for Young Scientists [grant number 502-14-01119172-41123]. The funding source had no role in the design of this study and had no role during its execution, analyses, interpretation of the data, or decision to submit results.

\section{Authors' contributions}

PB and MB-S designed the study; DS- enrolled patients and performed qualification for study intervention; DS, JK, MR, EM, and JW collected the data; SG performed the statistical analysis; MB-S, MG and DS wrote an article; PB made the critical review of article. All authors have read and approved the manuscript. 


\section{Acknowledgements}

Not applicable

\section{Availability of data and materials}

The datasets used and/or analyzed during the current study available from the corresponding author on reasonable request.

\section{Abbreviations}

n - sample size

yrs - years

T2D - Type 2 diabetes

CVD - Cardiovascular diseases

MET - Metabolic equivalent of task

BMI - Body mass index

WHR - Waist to hip ratio

PSS - Perceived Stress Scale

SES - Self-Esteem Scale

BSQ - Body Shape Questionnaire

FRS - Figure rating scale

CS - Current Silhouette

IS - Ideal Silhouette

TFEQ - Three-Factor Eating Questionnaire

CR - Cognitive Restraint of Eating

UE - Uncontrolled Eating 
EE - Emotional Eating

$r$ - correlation coefficient

$\delta$ - Delta

fMRI - functional magnetic resonance imaging

NS - not significant

\section{References}

1. Umpierre D, Ribeiro PA, Kramer CK, Leitão CB,Zucatti AT, Azevedo MJ, Gross JL, Ribeiro JP, Schaan BD. Physical activity advice only or structured exercise training and association with $\mathrm{HbA1c}$ levels in type 2 diabetes: a systematic review and meta-analysis. JAMA. 2011;305(17):1790-1799.

2. Pinckard K, Baskin KK, Stanford KI. Effects of Exercise to Improve Cardiovascular Health. Front Cardiovasc Med. 2019;6:69.

3. Marc-Hernández A, Ruiz-Tovar J, Aracil A, Guillén S, Moya-Ramón M. Impact of Exercise on Body Composition and Cardiometabolic Risk Factors in Patients Awaiting Bariatric Surgery. Obes Surg. 2019; doi:10.1007/s11695-019-04088-9.

4. Abd El-Kader SM, Al-Jiffri OH. Impact of weight reduction on insulin resistance, adhesive molecules and adipokines dysregulation among obese type 2 diabetic patients. Afr Health Sci. 2019;18(4):873883.

5. Hayashino Y, Jackson JL, Hirata T, Fukumori N,Nakamura F, Fukuhara S, Tsujii S, Ishii H. Effects of exercise on C-reactive protein, inflammatory cytokine and adipokine in patients with type 2 diabetes: a meta-analysis of randomized controlled trials. Metabolism. 2014;63:431-440.

6. Lugo D, Pulido AL, Mihos CG. The effects of physical activity on cancer prevention, treatment and prognosis: A review of the literature. Complement Ther Med. 2019;44:9-13.

7. Ramos RM, Coelho-Júnior HJ, Asano RY, Asano RY,Prado RCR, Silveira R, Urtado CB, de Lima LCR, Aguiar SDS, Prestes J, Medeiros AIA, Rodrigues B, de Oliveira Assumpção C. Impact of Moderate Aerobic Training on Physical Capacities of Hypertensive Obese Elderly. Gerontol Geriatr Med. 2019;5:2333721419859691.

8. Castro EA, Peinado AB, Benito PJ,Galindo M, Cupeiro R. What is the most effective exercise protocol to improve cardiovascular fitness in overweight and obese subjects? JSHS. 2017;6(4): 454-461.

9. Shin YA. How Does Obesity and Physical Activity Affect Aging?: Focused on Telomere as a Biomarker of Aging. J Obes Metab Syndr. 2019;28(2):92-104.

10. Bauman AE, Grunseit AC, Rangul V, Heitmann BL. Physical activity, obesity and mortality: does pattern of physical activity have stronger epidemiological associations? BMC Public 
Health.2017;17(1):788.

11. Sattelmair J, Pertman J, Ding EL, Kohl HW, Haskell W, Lee IM.Dose response between physical activity and risk of coronary heart disease. Circulation. 2011;124:789-795.

12. Saris WHM, Blair SN, van Baak MA, Eaton SB,Davies PS, Di Pietro L, Fogelholm M, Rissanen A, Schoeller D, Swinburn B, Tremblay A, Westerterp KR, Wyatt H. How much physical activity is enough to prevent unhealthy weight gain? Outcome of the IASO 1st Stock Conference and consensus statement. Obesity Rev. 2003;4:101-114.

13. Donnelly JE, Blair SN, Jakicic JM, Manore MM, Rankin JW, Smith BK; American College of Sports Medicine. American College of Sports Medicine Position Stand. Appropriate physical activity intervention strategies for weight loss and prevention of weight regain for adults. Med Sci Sports Exerc. 2009;41(2):459-471.

14. Swift DL, McGee JE, Earnest CP, Carlisle E, Nygard M, Johannsen NM. The Effects of Exercise and Physical Activity on Weight Loss and Maintenance. Prog Cardiovasc Dis. 2018;1(2):206-213.

15. Wiklund P, Alen M, Munukkaa E, Cheng SM, Yu B, Pekkalaa S, Cheng S. Metabolic response to 6-week aerobic exercise training and dieting inpreviously sedentary overweight and obese pre-menopausal women: A randomized trial. JSHS. 2014;3(3):217-224.

16. Hamasaki H, Kawashima Y, Tamada Y Furuta M,Katsuyama H, Sako A, Yanai H. Correction: Associations of Low-Intensity Resistance Training with Body Composition and Lipid Profile in Obese Patients with Type 2 Diabetes. PLoS One. 2015;10(8):e0137154.

17. Skrypnik D, Bogdański P, Mądry E, Karolkiewicz J,Ratajczak M, Kryściak J, Pupek-Musialik D, Walkowiak J. Effects of Endurance and Endurance Strength Training on Body Composition and Physical Capacity in Women with Abdominal Obesity. Obes Facts. 2015; 8(3):175-187.

18. Skrypnik D, Ratajczak M, Karolkiewicz J, Mądry E,Pupek-Musialik D, Hansdorfer-Korzon R, Walkowiak J, Jakubowski H, Bogdański P. Effects of endurance and endurance-strength exercise on biochemical parameters of liver function in women with abdominal obesity. Biomed Pharmacother. 2016;80:1-7.

19. Szulińska M, Skrypnik D, Ratajczak M, Karolkiewicz J,Madry E, Musialik K, Walkowiak J, Jakubowski $H$, Bogdański P. Effects of Endurance and Endurance-strength Exercise on Renal Function in Abdominally Obese Women with Renal Hyperfiltration: A Prospective Randomized Trial. Biomed Environ Sci. 2016;29(10):706-712.

20. Skrypnik D, Bogdański P, Skrypnik K, Mądry E,Karolkiewicz J, Szulińska M, Suliburska J, Walkowiak J. Influence of endurance and endurance-strength training on mineral status in women with abdominal obesity: a randomized trial. Medicine (Baltimore). 2019;98(12):e14909.

21. Maciaszek J, Skrypnik D, Ratajczak M, Stemplewski R, Osiński W, Bogdański P, Mądry E, Walkowiak $\mathrm{J}$, Karolkiewicz J. Two aerobic exercise programs in management of back pain among middle-aged obese women: a randomized controlled study. Hum. Mov. 2016;17 (2): 72-79.

22. Bernard P, Doré I, Romain A-J, Hains-Monfette G, Kingsbury C, Sabiston C. Dose response association of objective physical activity with mental health in a representative national sample of adults: A 
cross-sectional study. PLoS One. 2018;13(10):e0204682.

23. Rhodes RE, Janssen I, Bredin SSD, Warburton DER, Bauman A. Physical activity: Health impact, prevalence, correlates and interventions. Psychol Health. 2017;32(8):942-975.

24. Romain AJ, Marleau J, Baillot A. Association between physical multimorbidity, body mass index and mental health/disorders in a representative sample of people with obesity. J Epidemiol Community Health. 2019;73(9):874-880.

25. Brechan I., Kvalem IL. Relationship between body dissatisfaction and disordered eating: mediating role of self-esteem and depression. Eat Behav. 2015;17:49-58.

26. Osama AJ, Shehab Ael-K. Psychological wellbeing and biochemical modulation in response to weight loss in obese type 2 diabetes patients. Afr Health Sci. 2015;15(2):503-512.

27. Vancini RL, Rayes ABR, Lira CAB, Sarro KJ, Andrade MS. Pilates and aerobic training improve levels of depression, anxiety and quality of life in overweight and obese individuals. Arq Neuropsiquiatr. 2017;75(12):850-857.

28. Dhananjai S, Sadashiv, Tiwari S, Dutt K, Kumar R. Reducing psychological distress and obesity through Yoga practice. Int J Yoga. 2013;6(1):66-70.

29. Ten Hoor GA, Kok G, Peters GY, Frissen T, Schols AMWJ, Plasqui G. The Psychological Effects of Strength Exercises in People who are Overweight or Obese: A Systematic Review Med. 2017;47(10):2069-2081.

30. Ghroubi S, Elleuch H, Chikh T, Kaffel N, Abid M, Elleuch MH. Physical training combined with dietary measures in the treatment of adult obesity. A comparison of two protocols. Ann Phys Rehabil Med. 2009;52(5):394-413.

31. Ghroubi S, Kossemtini W, Mahersi S, Elleuch W, Chaabene M, Elleuch MH. Contribution of isokinetic muscle strengthening in the rehabilitation of obese subjects. Ann Phys Rehabil Med. 2016;59(2):8793.

32. Singh D, Singh D. Shape and significance of feminine beauty: an evolutionary perspective. Sex Roles. 2011;64:723-731.

33. Furnham A, Swami V, Shah K. Body weight, waist-to-hip ratio and breast size correlates of ratings of attractiveness and health. Pers Individ Differ.2006;41(3):443-454.

34. Platek SM, Singh D. Optimal waist-to-hip ratios in women activate neural reward centers in men. PLoS ONE. 2010;5:e9042.

35. Holliday IE, Longe OA, Thai NJ, Hancock PJ, Tovée MJ. BMI not WHR modulates BOLD fMRI responses in a sub-cortical reward network when participants judge the attractiveness of human female bodies. PLoS ONE. 2011;6:e27255.

36. Aquino MT, Orense C, Tanchoco CC, Amarra S, Gianan Tajan M, Dela Cruz EO. Correlates of Body Image Satisfaction Among Economically Depressed Urban Filipino Women. Philipp J Sci. 2009;138(1):67-74. 
37. Hai-Lun Ch. Body Image Change in Obese and Overweight Persons Enrolled in Weight Loss Intervention Programs: A Systematic Review and Meta-Analysis. PLoS One. 2015;10(5):e0124036.

38. Lasikiewicz N, Myrissa K, Hoyland A, Lawton CL. Psychological benefits of weight loss following behavioural and/or dietary weight loss interventions. A systematic research review. Appetite. 2014;72:123-137.

39. Weinberger NA, Kersting A, Riedel-Heller SG, Luck-Sikorski Body Dissatisfaction in Individuals with Obesity Compared to Normal-Weight Individuals: A Systematic Review and Meta-Analysis. Obes Facts. 2016;9(6):424-441.

40. Amissah Ch.M, Nyarko K, Gyasi-Gyamerah AA. Relationships among Body Image, Eating Behavior, and Psychological Health of University of Ghana Student. Int J Hum Soc Scien. 2015;5(6):192-203.

41. Manna P, Jain SK. Obesity, Oxidative Stress, Adipose Tissue Dysfunction, and the Associated Health Risks: Causes and Therapeutic Strategies. Metab Syndr Relat Disord. 2015;13(10):423-444.

42. Tomiyama AJ. Stress and Obesity. Annu Rev Psychol. 2015;70:703-718.

\section{Tables}


Table 1. Comparison of studied parameters before and after the intervention in groups A and B

(Anthropometric parameters were presented already in the paper by Skrypnik et al. 2015 ${ }^{17}$ )

\begin{tabular}{|c|c|c|c|c|c|c|c|}
\hline \multicolumn{2}{|l|}{ Variables } & $\begin{array}{l}\text { Group A before } \\
\text { intervention } \\
(\mathrm{n}=21)\end{array}$ & $\begin{array}{l}\text { Group A after } \\
\text { intervention } \\
(\mathrm{n}=21)\end{array}$ & $\begin{array}{l}\mathrm{p} \\
\text { value }\end{array}$ & $\begin{array}{l}\text { Group B before } \\
\text { intervention } \\
(n=17)\end{array}$ & $\begin{array}{l}\text { Group B after } \\
\text { intervention } \\
(\mathrm{n}=17)\end{array}$ & $\begin{array}{l}\mathrm{p} \\
\text { value }\end{array}$ \\
\hline \multicolumn{2}{|l|}{ Body mass [kg] } & $91.7 \pm 11.8$ & $89.5 \pm 11.8$ & $<0.001$ & $94.5 \pm 13.4$ & $91.8 \pm 13.7$ & 0.003 \\
\hline \multicolumn{2}{|l|}{$\mathrm{BMI}\left[\mathrm{kg} / \mathrm{m}^{2}\right]$} & $35.2 \pm 3.9$ & $34.3 \pm 3.9$ & $<0.001$ & $34.9 \pm 3.8$ & $33.9 \pm 4.1$ & $<0.001$ \\
\hline \multicolumn{2}{|c|}{$\begin{array}{l}\text { Waist circumference } \\
{[\mathrm{cm}]}\end{array}$} & $110.8 \pm 10.2$ & $105.5 \pm 11.1$ & $<0.001$ & $111.6 \pm 11.3$ & $104.0 \pm 10.5$ & $<0.001$ \\
\hline \multicolumn{2}{|c|}{$\begin{array}{l}\text { Hip circumference } \\
{[\mathrm{cm}]}\end{array}$} & $115.0 \pm 8.0$ & $111.7 \pm v 8.5$ & $<0.001$ & $115.8 \pm 9.4$ & $112.4 \pm 9.7$ & 0.001 \\
\hline \multicolumn{2}{|l|}{ WHR } & $0.96 \pm 0.06$ & $0.94 \pm 0.07$ & 0.01 & $0.96 \pm 0.07$ & $0.92 \pm 0.07$ & 0.01 \\
\hline \multicolumn{2}{|l|}{ PSS-10 } & $18.00 \pm 7.3$ & $17.1 \pm 7.2$ & NS & $18.8 \pm 7.4$ & $17.2 \pm 7.3$ & NS \\
\hline \multicolumn{2}{|l|}{ SES } & $29.1 \pm 4.6$ & $29.4 \pm 4.09$ & NS & $27.2 \pm 4.1$ & $28.3 \pm 4.3$ & NS \\
\hline \multicolumn{2}{|l|}{ BSQ-34 } & $97.4 \pm 23.07$ & $82.5 \pm 24.4$ & $<0.001$ & $99.2 \pm 30.2$ & $80.9 \pm 25.8$ & 0.01 \\
\hline \multirow[t]{3}{*}{ FRS } & CS & $6.62 \pm 0.92$ & $5.71 \pm 0.78$ & 0.001 & $6.70 \pm 1.16$ & $6.29 \pm 1.31$ & 0.01 \\
\hline & ID & $4.04 \pm 0.59$ & $4.00 \pm 0.63$ & NS & $4.12 \pm 0.60$ & $4.00 \pm 0.71$ & NS \\
\hline & $\mathrm{CR}$ & $14.5 \pm 3.1$ & $14.7 \pm 2.5$ & NS & $13.8 \pm 2.8$ & $15.5 \pm 2.6$ & 0.0 \\
\hline \multirow{2}{*}{ TFEQ-18 } & UE & $20.4 \pm 3.8$ & $19.3 \pm 3.7$ & NS & $20.5 \pm 4.6$ & $19.2 \pm 4.4$ & NS \\
\hline & $\mathrm{EE}$ & $6.8 \pm 2.5$ & $6.4 \pm 1.4$ & NS & $8.4 \pm 2.09$ & $7.6 \pm 2.001$ & 0.01 \\
\hline
\end{tabular}

NS - Not Significant 
e 2. Comparison of change in studied parameters from baseline to the 3-month point of the intervention in groups A and B (Anthropometric parameters were presented already in the paper by Skrypnik et al. $2015^{17}$ )

\begin{tabular}{|c|c|c|c|c|}
\hline \multicolumn{2}{|l|}{ Variables } & $\begin{array}{l}\text { Group A } \\
(\mathrm{n}=21)\end{array}$ & $\begin{array}{l}\text { Group B } \\
(\mathrm{n}=17)\end{array}$ & $\mathrm{p}$ value \\
\hline \multicolumn{2}{|l|}{$\delta$ Body mass $[\mathrm{kg}]$} & $-2.20 \pm 2.12$ & $-2.71 \pm 2.25$ & NS \\
\hline \multicolumn{2}{|l|}{$\delta$ BMI $\left[\mathrm{kg} / \mathrm{m}^{2}\right]$} & $-0.84 \pm 0.80$ & $-0.99 \pm 0.80$ & NS \\
\hline \multicolumn{2}{|l|}{$\delta$ Waist circumference $[\mathrm{cm}]$} & $-5.26 \pm 4.45$ & $-7.65 \pm 4.56$ & NS \\
\hline \multicolumn{2}{|l|}{$\delta$ Hip circumference $[\mathrm{cm}]$} & $-3.33 \pm 2.83$ & $-3.41 \pm 3.58$ & NS \\
\hline \multicolumn{2}{|l|}{$\delta$ WHR } & $-0.02 \pm 0.03$ & $-0.04 \pm 0.05$ & NS \\
\hline \multicolumn{2}{|l|}{$\delta$ PSS-10 } & $-0.90 \pm 5.64$ & $-1.71 \pm 4.66$ & NS \\
\hline \multicolumn{2}{|l|}{$\delta$ SES } & $0.33 \pm 2.43$ & $1.12 \pm 2.61$ & NS \\
\hline \multicolumn{2}{|l|}{6 BSQ-34 } & $-14.90 \pm 13.5$ & $-18.64 \pm 25.4$ & NS \\
\hline \multirow[t]{2}{*}{ FRS } & $\mathrm{CS}$ & $-0.90 \pm 0.83$ & $-0.41 \pm 0.50$ & 0.03 \\
\hline & IS & $-0.05 \pm 0.67$ & $-0.12 \pm 0.48$ & NS \\
\hline \multirow[t]{3}{*}{6 TFEQ-18 } & CR & $0.24 \pm 2.96$ & $1.65 \pm 2.06$ & NS \\
\hline & UE & $-1.05 \pm 3.90$ & $-1.29 \pm 3.38$ & NS \\
\hline & $\mathrm{EE}$ & $-0.43 \pm 2.09$ & $-0.82 \pm 1.28$ & NS \\
\hline
\end{tabular}

NS - Not Significant

Figures 


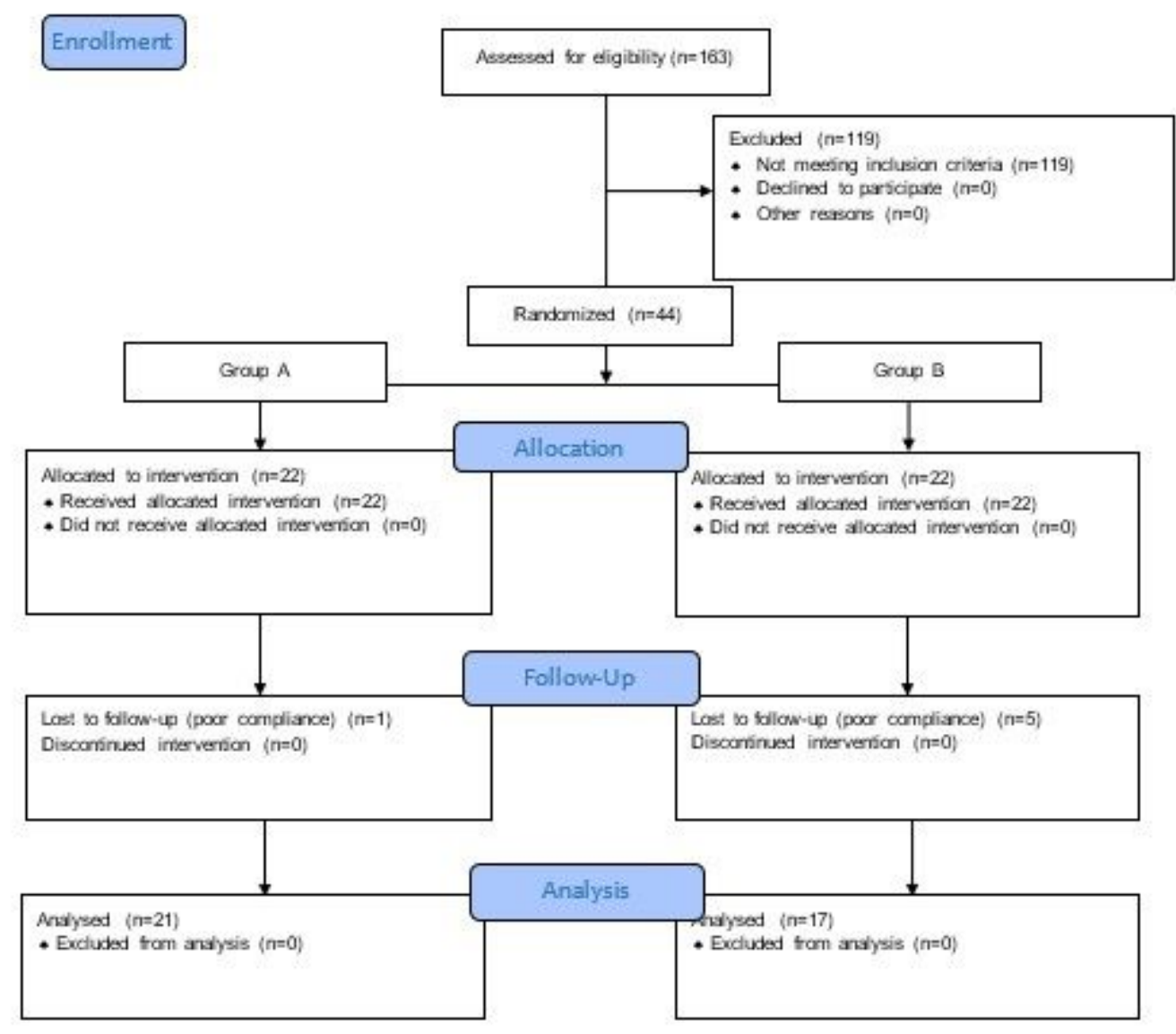

Figure 1

Flow diagram of study groups 


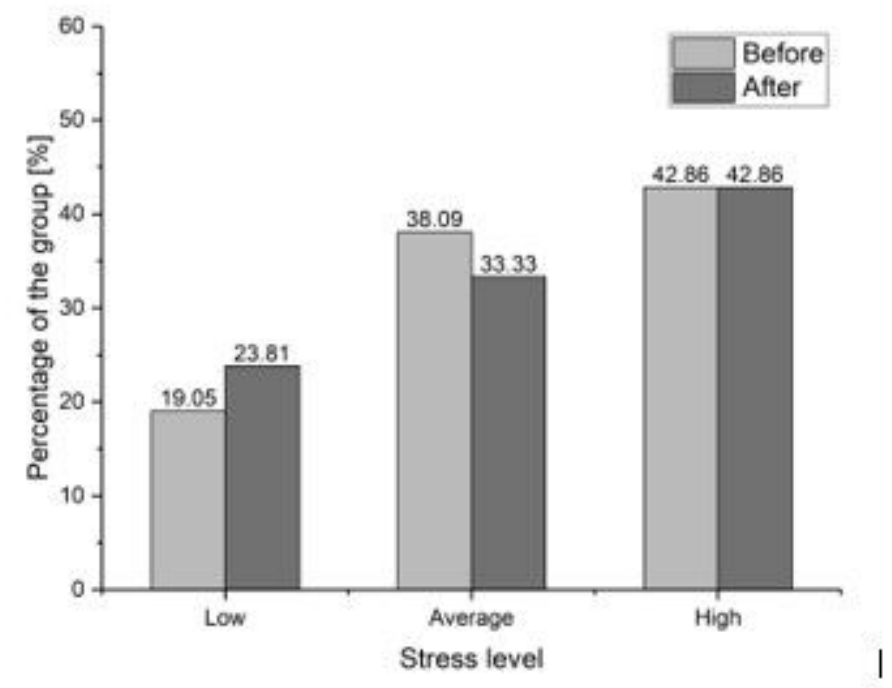

Figure 2A. Stress level initially and after 3 months of intervention in group A

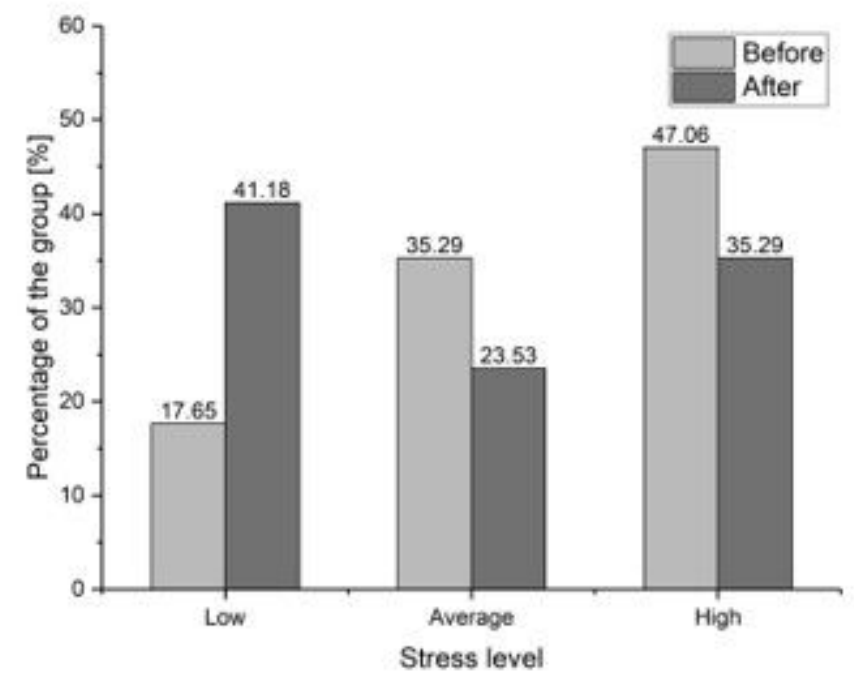

Figure 2B. Stress level initially and after 3 months of intervention in group B

\section{Figure 2}

A. Stress level initially and after 3 months of intervention in group A B. Stress level initially and after 3 months of intervention in group $B$ 


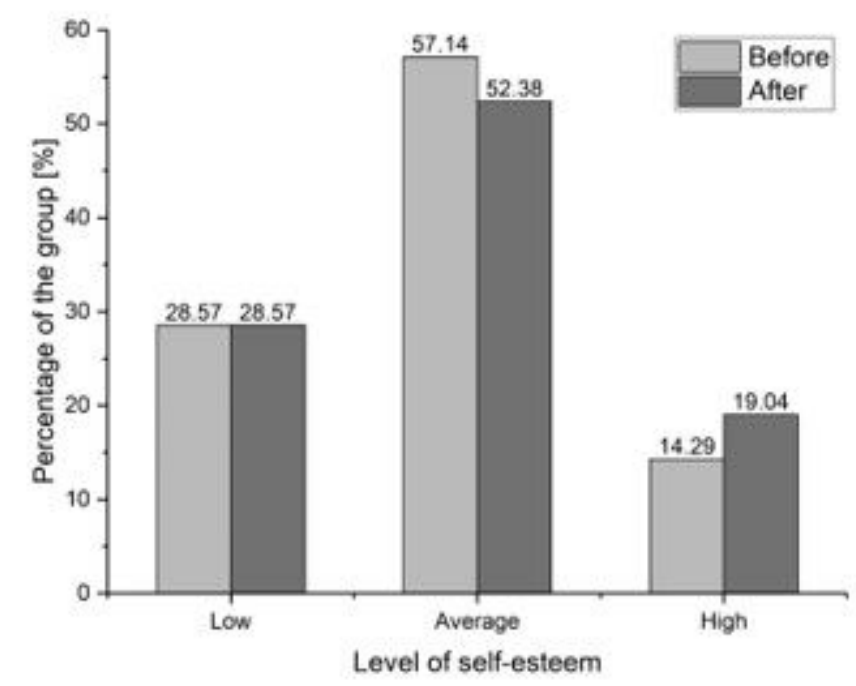

Figure 3A. Self-esteem level initially and after 3 months of intervention in group $A$

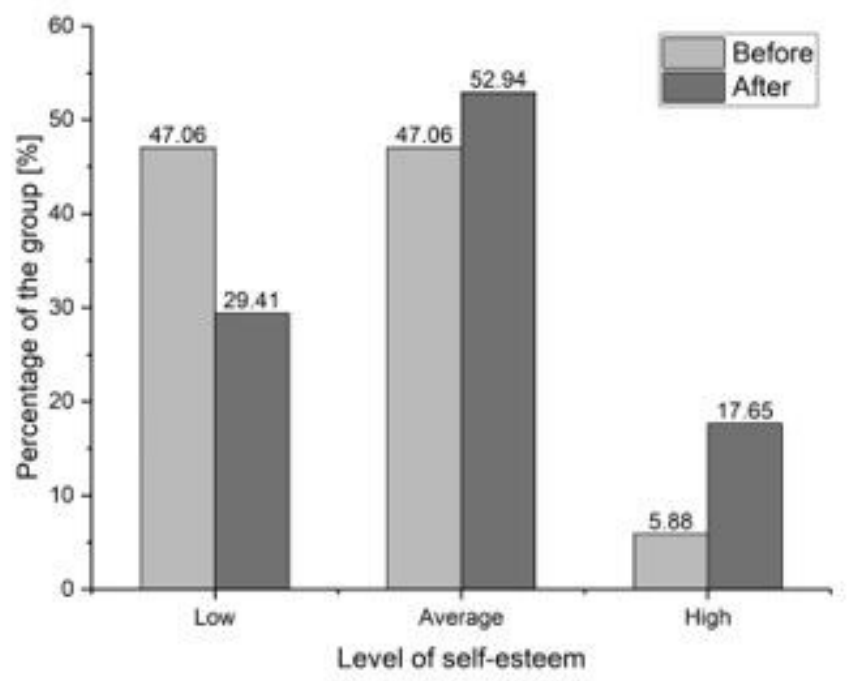

Figure 3B. Self-esteem level initially and after 3 months of intervention in group B

\section{Figure 3}

3A. Self-esteem level initially and after 3 months of intervention in group A 3B. Self-esteem level initially and after 3 months of intervention in group $B$

\section{Supplementary Files}

This is a list of supplementary files associated with this preprint. Click to download.

- CONSORT2010Checklist.pdf 